\title{
ОКИСЛЕНИЕ БЕНЗ(А)ПИРЕН-ХИНОНОВ
}

\section{2. ВОЗДЕИСТВИЕ ОКСИДАЗ НА 6-ГИДРОКСИБЕНЗ(А)ПИРЕН}

\author{
(Представил М. Губергриц)
}

Окислительное превращение бенз(а)пирена (БП), как и всех других аренов, протекает через образование гидроксипроизводных диолов и фенолов $\left[{ }^{1-3}\right]$. В ходе дальнейшего окисления образуются соответствующие хиноны $\left[{ }^{4-7}\right]$. При этом предполагается, что только первая стадия реакции - гидроксилирование арена - катализируется оксидоредуктазными ферментами, а дальнейшее превращение производных носит характер химического окисления, в котором ферменты не участвуют [5].

В данном сообщении сделана попытка оценить вклад ферментативного окисления в процесс дальнейшего превращения основного гидроксипроизводного БП - 6-гидроксиБП.

\section{Методика исследования}

Опыты проводили с 6-гидроксиБП* в концентрации $(1-3) \cdot 10^{-6} \mathrm{M}$ в $35 \%$-ном водном этаноле $(0,02 \mathrm{M}$ фосфатный буфер, $\mathrm{pH} 7,6)$. Оксидоредуктазными ферментами служили две оксидазы растительного происхождения - пероксидаза (ПО) из хрена (НПО «Биохимреактив», $R Z=2,75$, КФ 1.11.1.7) в концентрации от 0,05 до 8 мг/л и белковый препарат с о-дифенолоксидазной (ДФО, КФ 1.10.3.1 или по пересмотренному КФ 1.14.18.1) активностью, выделенный из клубней картофеля по методике [8].

Опыты проводили в реакторах объемом 10 мл, при механическом перемешивании и комнатной температуре. Через заданные промежутки времени отбирали пробы объемом 80 мкл и анализировали методом высокоэффективной жидкостной хроматографии на приборе «Knauer» (ФРГ) с флуоресцентным детектором фирмы «Perkin-Elmer» (США). Возбуждение при 315 нм и измерение при 402 нм. Чувствительность метода $2 \cdot 10^{-10}$ молей. Методика анализа более подробно описана в [ $\left.{ }^{9}\right]$.

\section{Результаты и обсуждение}

Судя по кинетическим кривым (рис. 1), окисление 6-гидроксиБП под воздействием кислорода воздуха и $0,1 \%$-ной перекиси водорода (кривые 1 и 2) протекает с заметной скоростью только в начальный период процесса (соответствующие начальные скорости см. в табл. 1). В дальнейшем, уже при конверсии субстрата на $6-7 \%$, наблюдается сильное торможение процесса его окисления. Более вероятной причиной этого,

* 6-ГидроксиБП синтезирован в Онкологическом научном центре АМН СССР В. П. Броновицкой, 


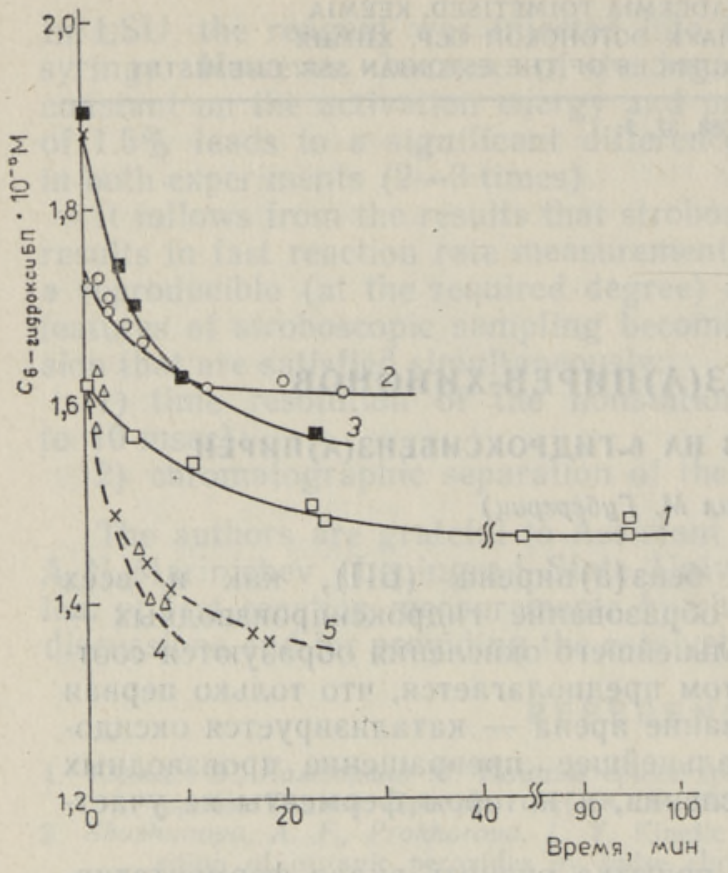

можно полагать, является образование хинонов БП, антиокислительные свойства которых доказаны ранее как относительно самого БП [9], так и относительно его фенолов и диолов [10]. Таким образом, налицо ярко выраженное автоингибирование процесса химического окисления 6-гидроксиБП.

Рис. 1. Кинетические кривые окисления 6-гидроксибенз (а) пирена под воздействием кислорода воздуха (1), $0,1 \%$-ной перекиси водорода (2), пероксидазы из хрена в количестве 0,16 (3) и $0,4 \mathrm{mr} / л(4)$, белкового препарата из клубней картофеля с о-дифенолоксидазной активностью $30 \mathrm{mr} / л$

(5). Условия опытов см. в тексте.

\section{Таблища 1}

Скорости окисления $\left(v_{0} \cdot 10^{-10} \mathbf{M} \cdot \mathbf{c}^{-1}\right)$ 6-гидроксиБП в различных системах и степень его разложения $(A, \%)$, при которой начинается торможение процесса

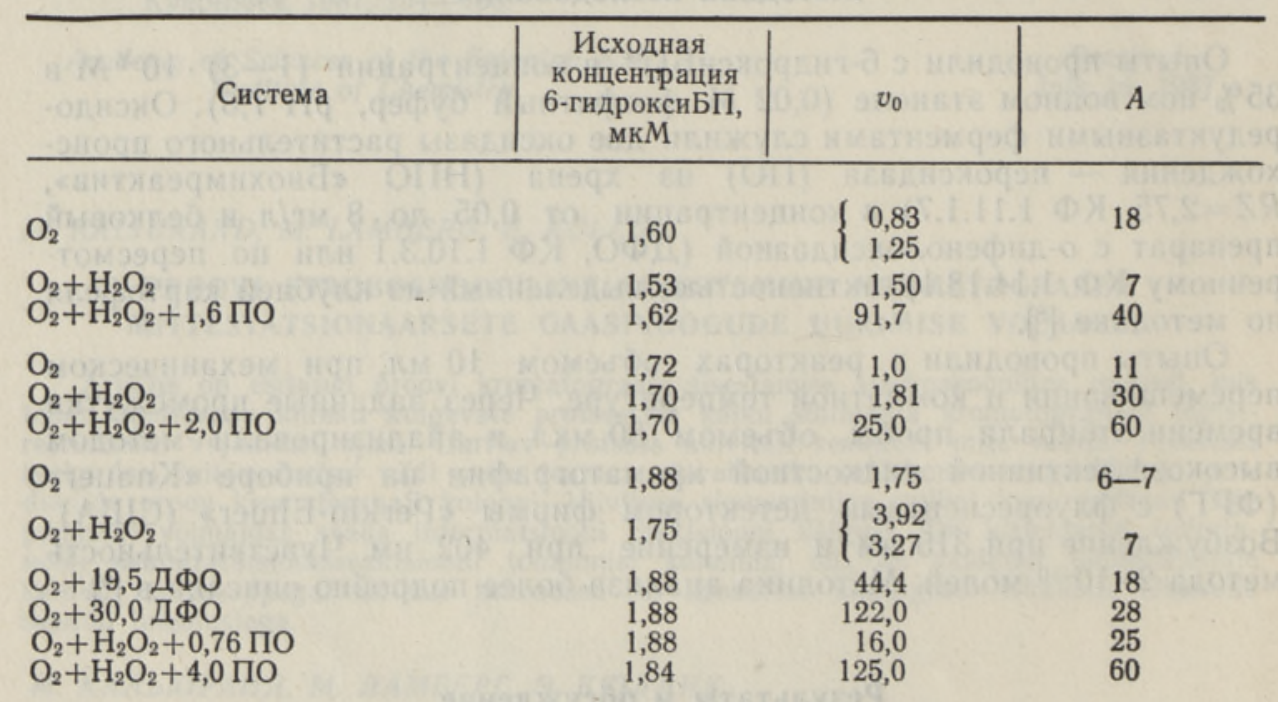

$\overline{П р и ~ м е ч ~ а ~ н ~ е . ~ К о н ц е н т р а ц и я ~ П О ~ и ~ Д Ф О ~ д а н а ~ в ~ м г / л . ~}$

Присутствие в системе белкового препарата с концентрацией протеина 30 мг/л (определенной по методу Лоури [ $\left.{ }^{11}\right]$ ) и ДФО-активностью способствовало ускорению деградации 6-гидроксиБП по сравнению с химическим окислением в тех же условиях почти на два порядка (табл. 1). В среднем на два порядка увеличивалась скорость превращения 6-гидроксиБП и при добавке ПО, при этом наблюдалась линейная концентрационная зависимость от навески фермента (табл, 2), 
Начальные скорости $\left(v_{0} \cdot 10-8 \mathrm{M} \cdot \mathrm{c}^{-1}\right)$ окисления 6-гидроксиБП А - различные его исходные концентрации (10-6 моль/л) и постоянная навеска ПО (6,0 мг/л);

Б - варьирование дозы ПО (мг/л) и постоянная концентрация 6-гидроксиБП $(0,7 \cdot 10-6$ моль/л)

\begin{tabular}{|c|c|c|c|}
\hline \multicolumn{2}{|c|}{ A } & \multicolumn{2}{|c|}{ Б } \\
\hline$c_{0}$ (6-гидроксиБП) & $v_{0}$ & $c_{0}(\Pi О)$ & $v_{0}$ \\
\hline 0,96 & 0,50 & 0,08 & 0,40 \\
\hline 1,40 & 0,68 & 0,11 & 0,46 \\
\hline 1,62 & 0,92 & 0,14 & 0,76 \\
\hline 1,84 & 1,25 & 0,31 & 1,60 \\
\hline 1,96 & 1,10 & 0,63 & 3,00 \\
\hline 2,42 & 1,35 & 1,57 & 8,00 \\
\hline 2,50 & 1,58 & & \\
\hline 3,20 & 3,00 & & \\
\hline
\end{tabular}

По формальнокинетическим расчетам экспериментальных данных с использованием дифференциального метода, концентрационный (истинный) порядок $\left(n_{c}\right)$ реакции по субстрату определяется навеской фермента: при концентрации ПО 0,46 мг/л (или $1,9 \cdot 10^{-6} M$ ) $n_{c}=1,68 \pm 0,14$, эффективная константа скорости $k_{\text {эфф }}=34,38 \cdot 10^{-4} \mathrm{c}^{-1}$; при повышении же дозы фермента (1,6 мг/л или $\left.4,0 \cdot 10^{-6} \mathrm{M}\right) n_{c}=1,105 \pm 0,015$ и $k_{\text {эфф }}=$ $=(12,73 \pm 1,06) \cdot 10^{-4} \mathrm{c}^{-1}$, т. е. при достаточном избытке фермента реакция становится псевдомономолекулярной, а не бимолекулярной, как при малых дозах ПО. Соответственно изменяются показатели по ферменту: $n_{\mathrm{c}}=0,977 \pm 0,032, k_{\text {эфф }}=1,115$ и $n_{\mathrm{c}}=0,463, k_{\text {эфф }}=5,67 \cdot 10^{-2} \mathrm{c}^{-1}$.

Автоингибирования, как такового, в реакции ферментативного окисления 6-гидроксиБП не наблюдается (рис. 1), а торможение процесса, которое становится заметным при низких дозах ДФО и ПО (табл. 1), очевидно, обусловлено недостатком фермента и начинается при $[S]_{0} /[E]_{0}>1$, где $S-$ субстрат и $E-$ фермент (рис. 2). Таким образом, при более чем 10-кратном избытке фермента реакция окисления БП-фенола протекала бы без торможения.

Рис. 2. Степень разложения 6-гидроксибенз (a) пирена $(A, \%)$, при которой начинается торможение процесса в зависимости от молярного соотношения субстрат/фермент.

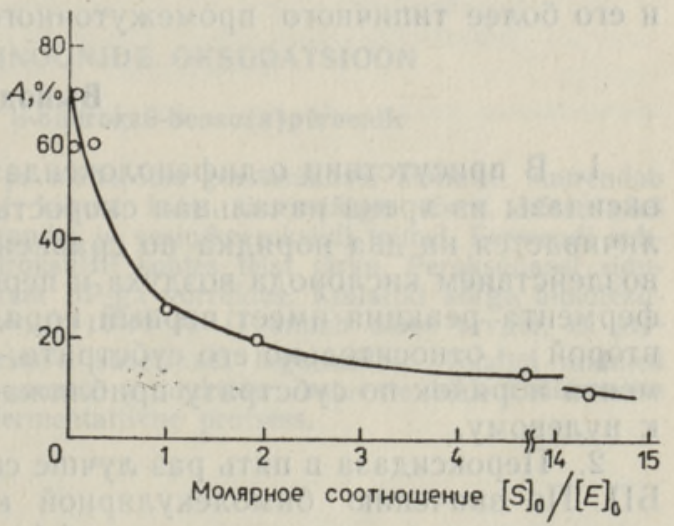

Показатели ферментативной кинетики для реакции субстрата с ферментом

$$
E+S \stackrel{K_{s}}{\rightleftarrows} E S \stackrel{k_{2}}{\longrightarrow} E+P
$$

вычисляли по уравнению Михаэлиса-Ментена

$$
v=\frac{k_{\text {каг }}[E]_{0}[S]_{0}}{K_{\mathbf{M} \text { (каж) }}+[S]_{0}}
$$


В модификации Лайнуивера-Берка $\left[{ }^{12}\right]$. Из графика $1 / v_{0}=f\left(1 /[E]_{0}\right)$ рассчитывали кажущуюся константу Михаэлиса $K_{\text {м(каж) }}=0,44$ мкM, которая в пять раз меньше $K_{M}$ для БП $(2,33$ мкM [13, 14]), что указывает на лучшее связывание ПО с 6-гидроксиБП, чем с БП. Напомним, что $K_{м}$ для 7,8 дигидро-дигидроксиБП с микросомальными оксидазами смешанной функции весьма близка - 0,41 мкM $\left[{ }^{10}\right]$, в то время как сам БП имеет в этой системе бо́льшее сродство, чем с оксидазами растительного происхождения, $-K_{M}=0,76$ мкM.

Каталитическая константа реакции $k_{\text {кат }}=8,8 \cdot 10^{-2} \mathrm{c}^{-1}$. Значение бимолекулярной константы ферментативной реакции, $k_{\text {кат }} / K_{\mathrm{M}}$, составляет $2,0 \cdot 10^{5} \mathrm{M}^{-1} \mathrm{c}^{-1}$. По принятой условной классификации $10^{4}<k_{\text {кат }} / K_{M}<10^{7}$, ПО можно считать активным относительно окисления 6-гидроксиБП ферментом.

Из сравнения полученных данных с результатами по влиянию ПО на одноатомные фенолы следует, что более сильный каталитический эффект наблюдается в случае полиядерных фенолов. Для оксибензола (монофенола) с исходной концентрацией $5 \cdot 10^{-4} \mathrm{M}$ при добавке ПО (50 мг/л) достигнуто увеличение начальной скорости лишь на один порядок: $v_{0} \cdot 10^{-5} \mathrm{M} \cdot \mathrm{c}^{-1}$ составляет 0,12 и 1,50 в системах с $\mathrm{H}_{2} \mathrm{O}_{2}$ и $\mathrm{H}_{2} \mathrm{O}_{2} /$ ПО соответственно [15].

Полученные данные подтверждают наше предположение о том, что ДФО и ПО, субстратами которых являются моноциклические фенолы, могут катализировать также окисление полиядерных фенолов, в частности 6-гидроксиБП. С другой стороны, его дальнейшее превращение протекает с большой скоростью и не является лимитирующей стадией общего процесса окисления арена. Отсутствие явления автоингибирования при окислении 6-гидроксиБП в присутствии обеих оксидаз может быть обусловлено тем, что в реакционной среде не накапливаются хиноны БП, так как они также претерпевают окисление под действием этих же ферментов.

Таким образом, есть основание полагать, что при наличии в организме соответствующих оксидоредуктаз ферментативный характер носит не только превращение самого исходного канцерогенного полиарена, но и его более типичного промежуточного производного - 6-гидроксиБП.

\section{Выводы}

1. В присутствии о-дифенолоксидазы из клубней картофеля и пероксидазы из хрена начальная скорость превращения 6-гидроксиБП увеличивается на два порядка по сравнению с химическим окислением под воздействием кислорода воздуха и перекиси водорода. При малых дозах фермента реакция имеет первый порядок относительно пероксидазы и второй - относительно его субстрата, с увеличением концентрации фермента порядок по субстрату приближается к первому, а по ферменту -. к нулевому.

2. Пероксидаза в пять раз лучше связывается с 6-гидроксиБП, чем с БП. По значению бимолекулярной константы $k_{\text {кат }} / K_{\mathrm{M}}=2 \cdot 10^{5} \mathrm{M}^{-1} \cdot \mathrm{c}^{-1}$ пероксидазу можно оценить как эффективный относительно окисления 6-гидроксиБП фермент. Это доказывает ферментативный характер дальнейшего окисления первичных продуктов превращения полиаренов соответствующих гидроксипроизводных.

\section{ЛИТЕ РА Т У Р А}

1. De Pierre, J. W., Ernster, L. The metabolism of polycyclic hydrocarbons and its relationship to cancer. - Biochim. Biophys. Acta, 1978, 473, 149-186.

2. Wiebel, F. J. Metabolism of monohydroxy-benzo(a) pyrenes by rat liver microsomes and mammalian cells in culture. - Arch. Biochem. Biophys., 1975, 168, N 6, $609-621$. 
3. Lesko, S., Lorentzen, W. C. R., Ts'o, P. O. P. Enzyme formation of 6-oxobenzo(a)pyrene radical for liver homogenates from carcinogenic benzo(a)pyrene. - Biochemistry, 1975, 14, N 18, 3978-3984.

4. Lind, C., Vadi, H., Ernster, L. Metabolism of benzo(a)pyrene-3,6-quinone and 3-hydroxy-benzo(a)pyrene in liver microsomes from 3-methylcholantrene-treated rats. - Arch. Biochem. Biophys., 1978, 90, N 1, 97-108.

5. Lorentzen, R. J., Caspary, W. J., Lesko, S. A., Ts'O, P. O. P. The autoxidation of 6-hydroxybenzo(a) pyrene and 6-oxobenzo(a) pyrene radical, reactive metabolites of benzo(a) pyrene. - Biochemistry, 1975, 14, N 18, 3970-3977.

6. Lesko, S. A., Lorentzen, R. J. Benzo(a) pyrene dione-benzo(a)pyrene diol oxidationreduction couples; involvement in DNA damage, cellular toxicity, and carcinogenesis. - J. Toxicol. Environ. Health., 1985, 16, 679-691.

7. Yagi, M. Oxidation of benzo(a)pyrene and 7,8-dihydro-7,8-dihydroxy benzo(a)pyrene by horseradish peroxidase- $\mathrm{H}_{2} \mathrm{O}_{2}$ intermediate: fluorometric study. - Cancer Biochem. Biophys., 1984, 7, 155-174.

8. Бузун $\Gamma_{.}$А. Выделение ферментов из растений в присутствии эндогенных фенолов. - Успехи биол. хим., 1972, 13, 102-115.

9. Коск М., Кирсо У. Окисление бенз(а)пирен-хинонов. 1. Воздействие кислорода воздуха и перекиси водорода. - Изв. АН ЭССР. Хим., 1987, 36, № 1, 53-59.

10. Shen, A. L., Fane, W. E., Wrighton, S. A., Jefcoate, C. P. Inhibition of benzo(a)pyrene and benzo(a)pyrene 7,8-dihydrodiol metabolism by benzo(a)pyrene quinones. - Cancer Res., 1979, 39, 4123-4129.

11. Lowry, O. H., Rosebrough, N. J., Farr, A. L., Randall, R. J. Protein measurement with the Folin phenol reagent. - J. Biol. Chem., 1951, 193, 265-275.

12. Березин Н. В., Мартинек К. Основы физической химии ферментативного катализа. M., 1977.

13. Kirso, U., Belykh, L., Stom, D. Kinetic of benzo(a)pyrene oxidation in aqueous solution. - Oxidation Communs, 1983, N $1-4,35-44$.

14. Kirso, U., Belykh, L., Stom, D., Irha, N., Urbas, E. Oxidation of benzo(a)pyrene by plant enzymes. - In: Polynuclear Aromatic Hydrocarbons: Formation, Metabolism and Measures. Proc. 7th Int. Symp. Columbus, 1982. Columbus, 1983, $679-687$.

15. Kirso, U., Belykh, L., Stom, D. Cooxidation of carcinogenic benzo(a)pyrene and phenols by horseradish peroxidase. - Acta Hydrochim. Hydrobiol., 1981, 9, $427-432$.
Ннститут химии
Академии наук Эстонской ССР
Поступила в редакцию
$20 / \mathrm{X} 1987$

\section{Marika KOSK, Uuve KIRSO}

\section{BENSO(A)POREEN-KINOONIDE OKSUDATSIOON}

\section{Oksüdaaside toime 6-hüdroksü-benso(a)püreenile}

Kartulimugulate $o$-difenooloksüdaasi ja mädarōika peroksüdaasi manulus suurendab 6-hüdroksü-benso (a) püreeni oksüdatsiooni kiirust kahe suurusjärgu võrra, kõrvutades selle substraadi lagunemiskiirusega õhuhapniku ja vesinikperoksiidi toimel. Fermendi suhtes on reaktsioon esimest järku ja 6-hüdroksüBP suhtes teist järku. Peroksüdaasi sidumine 6-hüdroksüBP-ga on viis korda parem BP-ga võrreldes. Küllaltki kõrge bimolekulaarse kiiruskonstandi väärtus $\left(k_{\text {cat }} / K_{M}=2,0 \cdot 10^{5} \mathrm{M}^{-1} \mathrm{~s}^{-1}\right)$ annab aluse arvata, et peroksüdaas on efektiivne katalüsaator uuritava substraadi lagunemisel. Toodud andmed annavad tunnistust, et ka polüareenide esmaste produktide vastavate hüdroksüühendite edasine lagunemine on oma iseloomult fermentatiivne protsess.

\section{Marika KOSK, Uuve KIRSO}

\section{OXIDATION OF BENZO(A)PYRENE QUINONES}

\section{Effect of oxidases on 6-hydroxy-benzo(a)pyrene oxidation}

The presence of potato tuber $o$-diphenoloxidase and horseradish peroxidase in the reaction mixture enhances the rate of oxidation of 6-hydroxy-benzo(a)pyrene about a hundred times. The oxidation reaction is first order to enzyme concentration and second order to its substrate concentration. The binding of 6-hydroxyBP by peroxidase is five times better than that of benzo(a)pyrene. A relatively high value of bimolecular rate constant $\left(k_{\text {cat }} / K_{\mathrm{M}}=2.0 \cdot 10^{5} \mathrm{M}^{-1} \mathrm{~S}^{-1}\right)$ shows that peroxidase is an efficient enzyme for degradation of this substrate. From these data it is clear that the degradation of polyarenes as well as their hydroxy derivatives is an enzymatic process. 